\title{
Novel combinatorial transdermal drug delivery of alendronate with risedronate for the treatment of osteoporosis
}

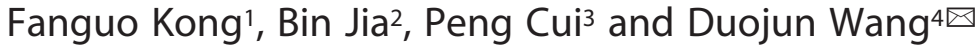 \\ 1Department of Minimally Invasive Spine Surgery, Luoyang Orthopedic Hospital of Henan Province, Zhengzhou City, Henan, 450018, China; \\ 2Integrated Orthopedic Department of Traditional Chinese Medicine (TCM) and Western Medicine Hong-Hui Hospital, Xi'an Jiaotong University \\ College of Medicine, Xi'an City, Shaanxi, 710054, China; ${ }^{3}$ Deparment of Orthopedics, Beijing Tongren Hospital, Biejing, China; ${ }^{4}$ Department of \\ Orthopedics, Shidong Hospital, Yangpu District, Shanghai, 200438, China
}

The presented investigation explores the efficiency of novel transdermal drug delivery system of combination of two drugs i.e risedronate and alendronate in the treatment of osteoporosis. The nanoparticulate transdermal patch was prepared using PLGA as principle polymer which has been found to be suitable for drug delivery. The novel formulation system was found to be more efficient in lowering and maintaining the plasma calcium at a normal level when compared to a pure drug in a study carried out on an excised rat skin.

Key words: alendronate, risedronate, PLGA, nanoparticles, transdermal patches, osteoporosis

Received: 13 August, 2019; revised: 30 September, 2019; accepted: 27 November, 2019; available on-line: 17 December, 2019

Ðe-mail: qxdks@sina.com

Acknowledgements of Financial Support: This project was funded by the Shanghai Health and Family Planning Commission (No. 20164Y0050)

Abbreviations: ALN, alendronate; PLGA, poly(lactic-co-glycolic acid); PVA, polyvinyl alcohol; HPMC, hydroxy propyl methyl cellulose; RSD, risedronate

\section{INTRODUCTION}

About 10 million women and men in the United States have osteoporosis, characterized mainly by low bone density and deterioration of architecture of bone that increase the risk of bone fractures (Blot et al., 2000; Nelson et al., 2010). Osteoporosis is a vital concern mostly in the geriatric population and about $55 \%$ of geriatric population in the United States has been estimated to be affected by it (World Health Organization; Selby, 1996). The two main important characteristics of the Osteoporosis are its adverse effects on microstructure and mass of the bones, and the consequent increased risk of fracture. According to WHO diagnostic criteria osteoporosis is defined by a bone mineral density $\mathrm{T}$ score of -2.5 or less and osteopenia by a low bone mass with bone mineral density T-score between -1 and -2.5 (Waugh et al., 2009). During the last few decades, the development of novel, highly effective therapeutics (e.g., bisphosphonates, strontium ranelate, etc) has remarkably extended the osteoporosis management spectrum. Depending on osteoporosis type, stage and the drugs used for treatment the relative risk of fractures can be maintained between $30 \%$ and $60 \%$. In the geriatric population as well as in patients treated with glucocorticoids, frequent falls are an independent risk factor causing both non-vertebral and vertebral fractures, which is correlated to the observed relative lack of efficacy of some bispho- sphonates in reducing hip fractures in very old patients with other risk factors besides low bone mineral density (Kim et al., 2006; Handa et al., 2008; Wade et al., 2014; Wells et al., 2008). Bisphosphonates are potent inhibitors of osteoclasts-mediated bone resorption and were found very effective in osteoporosis treatment. This effect is achieved by various mechanisms like promotion of apoptosis of mature osteoclasts leading to decreased bone remodeling, decreased osteoclast progenitors development, decreased osteoclasts recruitment.

\section{MATERIALS AND METHODS}

Materials. Alendronate (ALN) and Risedronate (RSD) were supplied by Baoji Guokang Bio-Technology Co., Ltd. (Baoji, Shaanxi, China) Span 80, PLGA (mol. Weight: 30000-60000), Methanol, Liquid paraffin, Trehalose, HPMC, Polyvinyl Alcohol (PVA) were of analytical grade and purchased from Shanghai Chemical Co. (Shanghai, China).

Methods. Preparation of Alendronate (ALD) and Risedronate (RSD) Nanoparticles by high-speed homogenization technique (Allemann et al., 1993).

The ALD and RSD loaded nanoparticles were prepared by high-speed homogenization technique. Span $80(0.2,0.4$ and $0.6 \%)$ solution was prepared in 100 $\mathrm{ml}$ of liquid paraffin to produce external phase. PLGA (100 mg, $150 \mathrm{mg}$ and $200 \mathrm{mg}$ ) and ALD and RSD (100 $\mathrm{mg}$ each) were dissolved in $20 \mathrm{ml}$ of methanol under sonication to produce an internal phase of dispersion. The internal phase of drug solution was added to the external liquid paraffin phase with a syringe at 15000 rpm in a high-speed homogenizer for 10-15 minutes. The whole system was kept under magnetic stirring for 6-8 hours until the complete evaporation of the internal phase (methanol). The resulting dispersion was centrifuged at $10000 \mathrm{rpm}$ for 20 minutes in order to separate the nanoparticles. The supernatant solution was used for determination of the encapsulation efficiency of RSD and ALD. The separated nanoparticles were freeze-dried using trehalose as cryoprotectant and used for further analysis. Prepared RSD and ALD-loaded PLGA nanoparticles were characterized and the optimized nanoparticles were used for the preparation. Composition of alendronate-risedronate nanoparticles (ALN-RSD-NP) is presented in Table 1.

Formulation of patches by Solvent casting evaporation method (Allemann et al., 1993; Dolatabadi et al., 2014).

Solvent casting evaporation method was used for the preparation of transdermal patches in a glass petri dish. 
Table 1. Composition of ALN-RSD-NP

\begin{tabular}{llll}
\hline Ingredients & F1 & F2 & F3 \\
\hline Alendronate $(\mathrm{mg})$ & 100 & 100 & 100 \\
\hline Risedronate $(\mathrm{mg})$ & 100 & 100 & 100 \\
\hline Methanol $(\mathrm{ml})$ & 20 & 20 & 20 \\
\hline PLGA $(\mathrm{mg})$ & 100 & 150 & 200 \\
\hline Span $80(\mathrm{ml})$ & 0.2 & 0.4 & 0.6 \\
\hline Liquid paraffin $(\mathrm{mg})$ & 100 & 100 & 100 \\
\hline
\end{tabular}

The baking membrane made of PVA was prepared by dissolving it in distilled water at $40^{\circ} \mathrm{C}$. This dispersion was poured into a glass petri dish followed by drying in a hot-air oven at $50^{\circ} \mathrm{C}$ for 8 hours. Optimized ALD and RSD nanoparticles were dispersed in aqueous HPMC solution under continuous stirring. During stirring, DBT was added drop-wise as a plasticizer. This nanoparticulate dispersion was cast onto the baking membrane and incubated at $50^{\circ} \mathrm{C}$ for 8 in the hot-air oven for drying. The patch was removed from the petri dish and cut into small pieces $(1 \times 1 \mathrm{~cm})$, wrapped in aluminum foil and kept in a desiccator for further analysis. Composition of the transdermal patches is presented in Table 2.

Table 2. Formulation batches of the transdermal patches

\begin{tabular}{lcccc}
\hline Ingredients & P1 & P2 & P3 & P4 \\
\hline PLGA-ALD-RSD NP eq. to $(\mathrm{mg})$ & 50 & 50 & 50 & 50 \\
\hline Polyvinyl alcohol $(\mathrm{mg})$ & 100 & 150 & 200 & 250 \\
\hline HPMC E5 LV $(\mathrm{mg})$ & 10 & 15 & 20 & 25 \\
\hdashline Dibutyl Pthalate (ml) & 0.1 & 0.2 & 0.3 & 0.4 \\
\hline Purified water $(\mathrm{ml})$ & 100 & 100 & 100 & 100 \\
\hline
\end{tabular}

Characterization of the nanoparticles (Catarina et al., 2006; Bououdina et al., 2013; Amudha et al., 2014; Dolatabadi et al., 2014; Monalisa et al., 2015).

Precentage encapsulation efficiency. The resulting nanoparticle dispersion was centrifuged at 10000 RPM for 20 minutes to separate the nanoparticles. The supernatant solution was used for the determination of encapsulation efficiency of RSD and ALD. The free amount of RSD and ALD in the supernatant was analyzed by HPLC method. $15 \mu$ of the supernatant solution was injected into a chromatograph equipped with a C18 column and UV detector. The mobile phase (80\% HPLC water: $20 \%$ Acetonitrile) flow rate was $2.5 \mathrm{ml} / \mathrm{min}$; the wavelength was set to $280 \mathrm{~nm}$. The percentage encapsulation efficiency (E.E) of the nanoparticles was calculated according to the following equation:

\section{$\%$ E.E $=$ Total drug-free drug/Total drug amount $\times 100$}

Particle size, PDI (Polydispersity index). Freezedried nanoparticles were dispersed in double-distilled water and sonicated for 20 minutes. Particle size was determined by laser diffraction particle size analyzer and PDI by dynamic light scattering (DLS) using a Zeta Nano ZS instrument.

Zeta potential. Zeta potential of RSD-ALN-NP was determined by dynamic light scattering (DLS) using a Zeta Nano ZS instrument.
In vitro drug release. The release of ALD and RSD from PLGA nanoparticles was determined by dialysis bag/membrane method. Nanoparticles equivalent to $20 \mathrm{mg}$ ALD and RSD were dispersed in $10 \mathrm{ml}$ of phosphate buffer $\mathrm{pH} 7.4$ in a dialysis tube tied at both ends and placed in $900 \mathrm{ml}$ of buffer solution at $37^{\circ} \mathrm{C}$ and stirred with a magnetic stirrer. $2 \mathrm{ml}$ of solution was withdrawn at defined time intervals and replenished with fresh solution to maintain sink condition. ALD and RSD release was measured by the HPLC method.

Characterization of ALD-RSD Transdermal patches (Khanna et al.,1997; Chandak et al., 2008; Ahmed et al., 2009; Saini et al., 1985).

Physical characterization. The prepared transdermal patches were inspected visually for color, clarity, smoothness, flexibility, thickness, weight variation and folding endurance.

Uniformity of ALD and RSD content. Three patches were dissolved separately in $40 \mathrm{ml}$ of methanol and the solution was filtered to remove the undissolved residues. The drugs content was determined by spectrophotometric measurement at $280 \mathrm{~nm}$.

Tensile strength. The tensile strength of the patch was determined for the assessment of the mechanical properties and strength of the patches was determined by using the universal strength testing apparatus (Hounsfield, Slinfold, Horsham, U.K.).

In vitro skin permeation study. In vitro drug release by the patches was determined using Franz diffusion cell. Rat abdominal skin was obtained from anesthetized rats after injection of pentobarbital $(35 \mathrm{mg} / \mathrm{kg})$. A piece of excised skin with a diameter of $20 \mathrm{~mm}$ was mounted (stratum corneum facing towards the donor compartment) on Franz diffusion cell between the receptor and donor compartment. A piece of the transdermal patch was applied to the stratum corneum. Receptor compartment was filled with $5 \mathrm{ml}$ of phosphate buffer at $37^{\circ} \mathrm{C}$. $0.3 \mathrm{ml}$ of the solution was withdrawn at defined time intervals from the receptor compartment and replaced with the equal volume of fresh solution. The withdrawn samples were analyzed by HPLC method as described in the previous section.

Hypercalcemia experiment. To study the hypercalcemia effect and to establish a hypercalcemia-like state $2.5 \mathrm{mg} / \mathrm{kg} /$ day of $1-(\mathrm{OH})-\mathrm{D} 3$ was administered intraperitoneally to male S.D. rats during the experiment. Immediately after or 5 days after the first $1 \alpha(\mathrm{OH}) \mathrm{D} 3$ administration, ALD-RSD nanoparticulate patches (P4) were applied to the rats on dehaired abdomen for $24 \mathrm{~h}$ at a dose of $0.4 \mathrm{mg}$ and $1.6 \mathrm{mg}$ of alendronate $/ \mathrm{kg}$. Separately, $1.6 \mathrm{mg} / \mathrm{kg}$ alendronate was administered orally to the rats. At determined time intervals, blood was withdrawn from the cervical vein of the rats under ether anesthesia. To prevent coagulation anticoagulant heparin sulfate was used. The plasma was separated from the other components of blood by centrifugation. Calcium concentrations in the plasma were determined by Calcium E test Wako (Wako Pure Chemical Industries, Osaka, Japan) (Bourges et al., 2003)

\section{RESULTS AND DISCUSSION}

The EE was found to be higher in all formulations prepared by high-speed homogenization method. Oil-inoil solvent evaporation method played a significant role in obtaining higher EE by reducing solubilisation chances of both ALD and RSD in the external liquid paraffin phase. Both drugs are insoluble in the external phase, 
Table 3. Characterization of ALN-RSD-NP patches.

\begin{tabular}{llll}
\hline Parameter & F1 & F2 & F3 \\
\hline EE $(\%)$ & 89.90 & 96.92 & 99.80 \\
\hline Particle size $(\mathrm{nm})$ & 243 & 359 & 392 \\
\hline PDI & 0.45 & 0.35 & 0.25 \\
\hline Zeta Potential $(\mathrm{mV})$ & 20 & -35 & 25 \\
\hline
\end{tabular}

which improved the EE of nanoparticles. The EE was in the range of 89.90 to $99.80 \%$. The direct relation was observed between EE and the concentration of PLGA. A thick polymeric dispersion was formed due to an increased concentration of PLGA in a fixed volume of methanol that resulted in maximum entrapment of both drugs in the polymeric matrix system. The particle size was determined using laser diffraction particle size analyzer. The particle size was in the range of 243-392 nm. Direct relation was observed between PLGA concentration and particle size. Increase in the amount of polymer concentration resulted in increased particle size. F3 formulation showed PDI of 0.25 which was desired for the nanoparticulate system. Zeta potential of nanoparticles was determined using DLS system and was in the

Table 4. In vitro drug release from ALN-RSD-NP

\begin{tabular}{lllllll}
\hline Time (h) & F1 & & F2 & \multicolumn{3}{l}{ F3 } \\
\hline & ALD & RSD & ALD & RSD & ALD & RSD \\
\hline 0 & 0 & 0 & 0 & 0 & 0 & 0 \\
\hline 2 & 20.12 & 18.24 & 17.19 & 15.13 & 12.11 & 13.15 \\
\hline 4 & 35.89 & 21.43 & 21.23 & 23.67 & 23.98 & 20.87 \\
\hline 6 & 43.90 & 42.65 & 31.47 & 42.87 & 32.67 & 36.98 \\
\hline 8 & 62.13 & 67.48 & 47.87 & 62.09 & 54.87 & 53.87 \\
\hline 10 & 73.90 & 89.64 & 68.98 & 87.98 & 69.65 & 61.87 \\
\hline 12 & 97.12 & 98.67 & 89.14 & 90.12 & 79.11 & 75.12 \\
\hline
\end{tabular}

Table 5. Physical characterization of the transdermal patches

\begin{tabular}{llllllll}
\hline Batch & Appearance & Thickness & Weight $(\mathrm{g})$ & Folding endurance & Drug content $\%$ & $\%$ moisture loss & \% moisture absorbed \\
\hline P1 & ST & 0.029 & 0.14 & 209 & 93.56 & 0.15 & 1.4 \\
\hline P2 & T & 0.062 & 0.17 & 143 & 94.46 & 1.8 & 2.0 \\
\hline P3 & ST & 0.075 & 0.13 & 198 & 97.45 & 3.1 & 1.38 \\
\hline P4 & ST & 0.048 & 0.18 & 225 & 99.51 & 2.3 & 3.1 \\
\hline
\end{tabular}

T, transparent; S, smooth, ST, smooth transparent; R, rough; HR, hard and rough

Table 6. Assessment of ALN and RSD permeation through rat skin.

\begin{tabular}{|c|c|c|c|c|c|c|c|c|}
\hline Time (h) & P1 & & P2 & & P3 & & P4 & \\
\hline & ALD & $\mathrm{RSD}$ & ALD & $\mathrm{RSD}$ & ALD & RSD & ALD & RSD \\
\hline 0 & 0 & 0 & 0 & 0 & 0 & 0 & 0 & 0 \\
\hline 2 & 13.67 & 16.87 & 19.98 & 21.09 & 19.98 & 24.87 & 15.98 & 10.98 \\
\hline 4 & 21.56 & 28.87 & 24.87 & 32.89 & 32.87 & 38.98 & 25.98 & 29.09 \\
\hline 6 & 38.78 & 39.87 & 40.98 & 50.09 & 45.87 & 45.98 & 39.09 & 31.98 \\
\hline 8 & 50.98 & 56.87 & 62.09 & 71.20 & 53.98 & 54.98 & 47.98 & 43.98 \\
\hline 10 & 76.80 & 69.76 & 78.98 & 89.98 & 71.98 & 76.98 & 59.87 & 57.98 \\
\hline 12 & 97.78 & 89.98 & 95.86 & 90.98 & 97.87 & 87.09 & 70.98 & 68.78 \\
\hline
\end{tabular}

range of -35 to $25 \mathrm{mV}$. Zeta potential of $\mathrm{F} 3$ formulation was $25 \mathrm{mV}$ which indicated a moderate degree of stability due to inner particle repulsion (Cascone et al., 2002). Results are presented in Table 3 below.

In vitro drug release pattern of ALN-RSD is shown in Table 4.

The amount of drug released from polymers largely depended on solvent compatibility, cross-linking as well as on the nature of the polymer. Ionic interactions, mass transfer limitation also contributed to the drug release. The drug release from PLGA nanoparticles was in the range of $75.12-97.13 \%$ during $12 \mathrm{~h}$. The formulation batch F3 showed an extended release up to $75.12 \%$ which was due to the high concentration of PLGA polymer in it. The strategies like coating of active drugs can greatly help in reducing the toxic effects of some drugs by preventing their direct contact with the tissue (Sahoo et al., 2013).

\section{Characterization of the transdermal patches containing ALN-RSD-NP}

Solvent casting method was used to formulate ALNRSD-NP patch from the optimized batch of formulation F3. Next, the prepared patch was evaluated for thickness, weight variation, folding endurance, drug content uniformity, tensile strength, percent moisture absorption, percent moisture loss, in vitro drug release, and in hypocalcaemia experiment. The results obtained are depicted in Table 5. When evaluated for physical appearance the films were found to be flexible, uniform, and smooth with a transparent surface. Batches of formulations showed uniformity in their weight, thickness, and folding endurance and diameter. The patches showed a thickness from $0.025 \pm 0.01 \mathrm{~mm}$ to $0.075 \pm 0.02 \mathrm{~mm}$. The average weight was found to be between $0.13 \pm 2 \mathrm{~g}$ and $0.17 \pm 1 \mathrm{~g}$. The folding endurance was of $140-225$ with drug content between 94.46-99.47\%. The percentage of moisture absorbed ranged between $1.3 \pm 0.20$ and $2.1 \pm 0.21$ while moisture loss percentage was between

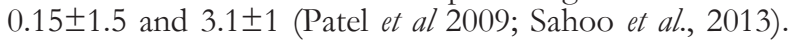




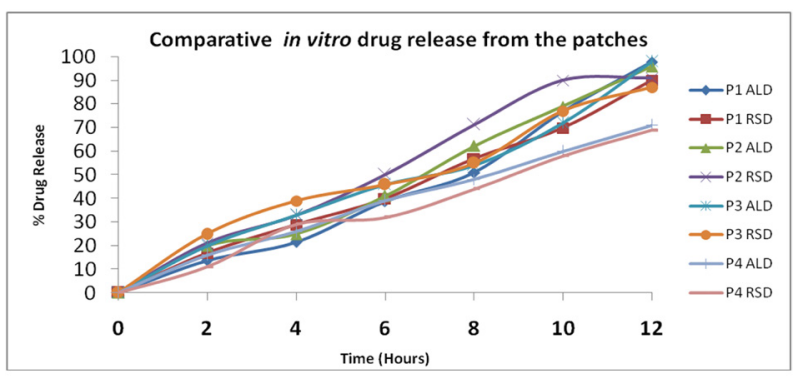

Figure 1. Graphical representation of ALN-RSD permeation through the patches

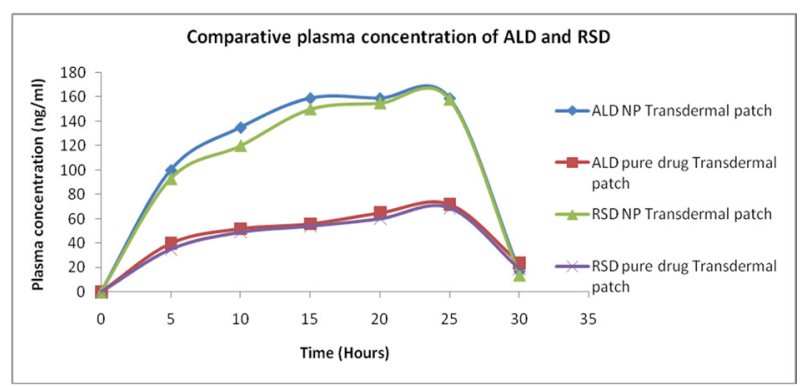

Figure 2. Comparative plasma concentration of ALD and RSD

The in vitro skin permeation study was carried out and results were plotted as graph as shown in Fig. 1. Patches containing ALN-RSD-NP were subjected to in vitro rat abdominal skin permeation study. The selected formulation was applied to the stratum corneum of the skin of the separated portion of rat abdominal skin. The receptor compartment of the cell was filled with $3 \mathrm{ml}$ of phosphate buffer solution $\mathrm{pH}$ 7.4. The permeation of Alendronate was found to be from $70.98 \%$ to $89.11 \%$ while that of Risedronate was from $68.98 \%$ to $92.11 \%$ over the period of 12 hours. The results are shown in Table 6 . The formulation batch P4 was considered the most optimized due to the highest drug content of $99.51 \%$ and prolonged skin permeation $(68.98 \%$ and $70.68 \%$ of Risedronate and Alendronate respectively).

Figure 2 and Fig. 3 shows the comparative plasma concentration of ALN-RSD when administered as pure drugs and in nanoparticulate form. As presented in Table 7, ALD, as well as RSD, administered as pure drug rapidly vanished from blood circulation $(\mathrm{BA}=1.3$ and 1.1 for ALD and RSD respectively) whereas after administration of ALD and RSD in the form of transdermal patches their plasma concentration raised gradually. The bioavailability (BA) was also increased during the first few hours after administration of a dose of 12 $\mathrm{mg} / \mathrm{kg}$ and $10 \mathrm{mg} / \mathrm{kg}$ for ALD and RSD respectively Table 7. Data for pharmacokinetic parameters of ALD and RSD in the form of a patch with pure drugs and the nanoparticulate.

\begin{tabular}{llclc}
\hline \multirow{2}{*}{ Parameters } & \multicolumn{2}{l}{$\begin{array}{l}\text { Transdermal Patch with } \\
\text { Pure drug (ALD and } \\
\text { RSD) }\end{array}$} & $\begin{array}{l}\text { Transdermal Patch } \\
\text { with NP }\end{array}$ \\
\hline & ALD & RSD & ALD & RSD \\
\hline Dose $(\mathrm{mg} / \mathrm{kg})$ & 30 & 37 & 12 & 10 \\
\hline AUC $(\mathrm{ng} \cdot \mathrm{h} / \mathrm{mL})$ & 905 & 897 & 98 & 89 \\
\hline BA $(\%)$ & 1.3 & 1.1 & 6.4 & 7.6 \\
\hline
\end{tabular}

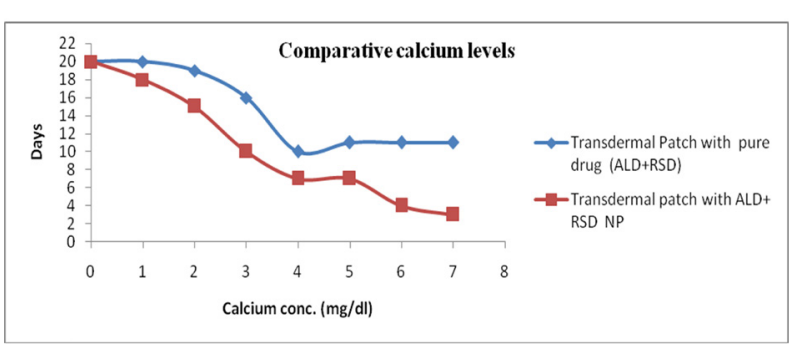

Figure 3. Plasma calcium concentration profile in hypercalcemia rat model treated with two different transdermal patch formulations (Pure drugs and Drugs in nanoparticles)

in case of the patches (Pandit et al., 2009). After that, the plasma concentration was steady over 24 hours. The results confirmed almost six to seven-fold increase in bioavailability when drugs were administered in the nanoparticulate form. The pharmacokinetic parameters observed are shown in Table 7.

\section{Hypercalcemia experiment}

The data for plasma calcium concentration profile in hypercalcemia rat model from two different transdermal patch formulations is presented in Table 8. The data suggests the usefulness of the formulation in lowering the plasma calcium level in rats treated with transdermal patches containing CS-ALN-NP while patches containing pure alendronate failed to show a significant decrease in plasma calcium level. In this experiment, plasma calcium concentration was reduced from $15 \mathrm{mg} / \mathrm{dl}$ to $8 \mathrm{mg} / \mathrm{dl}$ (4 times more) for ALD and from $15 \mathrm{mg} / \mathrm{dl} \mathrm{to} 4 \mathrm{mg} / \mathrm{dl}$ for RSD in rat groups treated with transdermal patches with CS-ALN-NP for a week, while the final concentration was only $12 \mathrm{mg} / \mathrm{dl}$ (ALD) and $10 \mathrm{mg} / \mathrm{dl}$ (RSD) in case of transdermal patches containing the pure drugs (ALD and RSD).

Alendronate is the first-choice drug for the treatment of hypercalcemia in malignancy and osteoporosis (Pandit et al., 2009). The plasma calcium level concentration study confirmed that RSD-ALN-NP delivered transdermally had a substantially greater effect on plasma calcium level than pure drugs and also the bioavailability was higher when compared to pure RSD-ALN. These results (enhanced skin permeation, enhanced bioavailability and decrease of calcium level) proved that transdermal patches with RSD-ALN-NP inhibit the function of osteoclasts which mediate bone

Table 8. Plasma calcium concentration profile of ALD-RSD.

\begin{tabular}{|c|c|c|}
\hline \multirow[b]{2}{*}{ Days } & \multicolumn{2}{|c|}{ Plasma calcium concentration (mg/dl) } \\
\hline & $\begin{array}{l}\text { Transdermal Patch } \\
\text { with pure drugs } \\
\text { (ALD+RSD) }\end{array}$ & $\begin{array}{l}\text { Transdermal patch with } \\
\text { ALD+ RSD NP }\end{array}$ \\
\hline 0 & 20 & 20 \\
\hline 1 & 20 & 18 \\
\hline 2 & 19 & 15 \\
\hline 3 & 16 & 10 \\
\hline 4 & 10 & 7 \\
\hline 5 & 11 & 7 \\
\hline 6 & 11 & 4 \\
\hline 7 & 11 & 3 \\
\hline
\end{tabular}


resorption and lead to preventive and therapeutic effects in the treatment of osteoporosis and hypercalcemia (Pandit et al., 2009).

\section{CONCLUSION}

The transdermal patches of ALN-RSD-NP were formulated successfully for anti-osteoporetic treatment. The proposed formulation showed reliable bioavailability which was six to seven times higher than that of pure drugs. The plasma calcium level was maintained by formulations containing ALN-RSD-NP which found to be useful in controlling the osteoporosis. These findings such as enhanced skin permeation, bioavailability and the lower plasma calcium level after transdermal delivery suggest that this is a promising approach for the treatment of osteoporosis.

\section{REFERENCES}

Ahmed MG, Charyulu RN, Harish NM, Prabhu P (2009) Formulation and in-vitro evaluation of chitosan films containing Tetracycline for the treatment of periodontitis. Asian J. Pharm. 113-119. link.springer.com/article/10.1208/s12249-010-9464-2

Allemann E, Gurny R, Deolker E (1993) Drug loaded nanoparticles: preparation methods and drug targeting issues. Eur. J. Pharm. Biopharm. 39: 173-191. https://doi.org/10.1016/j.nano.2009.04.001

Amudha M, Krishna K, Shanmuga S (2014) Biosynthesis and characterization of silver nanoparticles using the aqueous extract of Vitex negundo. Linn. World J. Pharm. Pharm. Sci. 3: 1385-1393. https://doi. org/10.1016/j.jksus.2017.05.013

Blot L, Marcelis A, Devogelaer JP, Manicourt DH (2000) Effects of diclofenac, aceclofenac and meloxicam on the metabolism of proteoglycans and hyaluronan in osteoarthritic human cartilage. $\mathrm{Br}$. J. Pharmacol. 131: 1413-1421. https://doi.org/10.1038/sj.bjp.0703710

Bououdina MS, Rashdan JL, Bobet Y, Ichi Y (2013) Nanomaterials for biomedical applications: synthesis, characterization, and applications. J. Nanomater. 240 8501. https://doi.org/10.1155/2013/962384

Bourges JL, Gautier SE, Delie F (2003) Ocular drug delivery targeting the retina and retinal pigment epithelium using polylactide nanoparticles. Invest. Ophthalmol. Vis. Sci. 44: 3562-3569. https://doi. org/10.1167/iovs.02-1068

Cascone MG, Lazzeri L, Carmignani C (2002) Gelatin nanoparticles produced by a simple W/O emulsion as delivery system for methotrexate. J. Mater. Sci. Mater. Med. 13: 523-526. https://doi. $\operatorname{org} / 10.1023 / \mathrm{a}: 1014791327253$

Chandak AR, Verma PRP (2008) Development and evaluation of HPMC based matrices for transdermal patches of Tramadol. Clin. Res. Regul. Affairs 25: 13-30. https://doi.org/10.1208/s12249-0150322-0

Dolatabadi EN, Hamishehkar H, Eskandani M. Valizadeh H (2014) Formulation, characterization and cytotoxicity studies of alendronate sodium loaded solid lipid nanoparticles. Colloids. Surf. B. Biointerfaces. 117: 21-28. https://doi.org/10.1016/j.colsurfb.2014.01.055

Handa R, Ali KA, Maalouf G (2008) Osteoporosis in developing countries. Best. Pract. Res. Clin. Rheumatol. 22: 693-708. https://doi. org/10.1016/j.berh.2008.04.002

Khanna R, Agarwal SP, Ahuja A (1997) Preparation and evaluation of mucoadhesive buccal films of clotrimazole for oral candida infections. Indian J. Pharm. Sci. 59: 299-305

Kim DH, Vaccaro AR (2006) Osteoporotic compression fractures of the spine; current options and considerations for treatment. The Spine J. 6: 479-487. https://doi.org/10.1016/j.spinee.2006.04.013

Monalisa P, Nayak PL (2015) Green synthesis and characterization of zero valent iron nanoparticles from the leaf extract of Azadirachta indica (Neem). Int. J. Curr. Microbiol. App. Sci. 4: 379-386. https:// doi.org/10.1515/ntrev-2015-0023

Nelson HD, Haney EM, Chou R, Dana T, Fu R, Bougatsos C (2010) Screening for osteoporosis: Systematic review to update the 2002 U.S. Preventive Services Task Force Recommendation [Internet]. Agency for Healthcare Research and Quality. PMID: 20722176

Pandit V, Khanum A, Bhaskaran S, Banu V (2009) Formulation and evaluation of transdermal films for treatment of overactive bladder. Int. J. Pharm. Tech. Res. 1: 799-804. https://dx.doi.org/10.22377/ajp. v4i1.327

Patel RP, Patel G, Baria A (2009) Formulation and evaluation of transdermal patch of Aceclofenac. Int. J. Drug Delivery 1: 41-51. http:// doi.org/10.19080/GJPPS.2018.04.555647

Reis PR, Neufeld RJ, Veiga FJ (2006) Nano capsulation 1. Meth-od of preparation of drug - loaded polymeric nanoparticles. Nano Technol. Biol. Med. 2: 8-21. https://doi.org/10.1016/j.nano.2005.12.003

Sahoo BJ, Mishra AN (2013) Formulation and evaluation of transdermal patches of diclofenac. World J. Pharma. Pharma. Sci. 2: 49654971. https: / /doi.org/10.19080/GJPPS.2018.04.555647

Saini TR, Seth AK, Agrawal GP (1985) Evaluation of free films. Indian Drugs 23: 45-47. https://doi.org/10.25004/IJPSDR.2018.100417

Selby P (1996) Alendronate treatment for osteoporosis: a review of the clinical evidence. Osteoporosis Int. 6: 419-426. https://doi. org/10.1007/bf01629572

Wade SW, Strader, C, Fitzpatrick LA, Anthony MS, O’Malley CD (2014) Estimating prevalence of osteoporosis: examples from industrialized countries. Arch. Osteoporosis 9: 182. https://doi.org/10.1007/ s11657-014-0182-3

Waugh EJ, Lam MA, Hawker GA, McGowan J, Papaioannou A, Cheung AM, Hodsman AB, Leslie WD, Siminoski K, Jamal SA (2009) Risk factors for low bone mass in healthy 40-60 year old women: a systematic review of the literature. Osteoporos Int. 20: 1-21. https://doi.org/10.1007/s00198-008-0643-x

World Health Organization. Chronic Rheumatic Conditions. https:// www.searchencrypt.com/search?eq=TPYDLzCBX5DCKxpyVW7A wkga0yb17PkHKC5FgnSv29uG3iTWcq4HSxtmwUk9mPBcr\%2Flq mfds70andTnixp4rmQ $\% 3 \mathrm{D} \% 3 \mathrm{D} \& \mathrm{ptc}=: / /$ mail

Wells GA, Cranney A, Peterson J, Boucher M, Shea B, Robinson V, Coyle D, Tugwell P (2008) Alendronate for the primary and secondary prevention of osteoporotic fractures in postmenopausal women. Cochrane Database Syst. Rev. 23: CD001155. https://doi. org/10.1002/14651858.CD001155.pub2. 